\title{
Born which Way? ADHD, Situational Self-Control, and Responsibility
}

\author{
Polaris Koi $(\mathbb{D}$
}

Received: 8 December 2019 / Accepted: 15 June 2020 / Published online: 25 June 2020

(C) The Author(s) 2020

\begin{abstract}
Debates concerning whether Attention Deficit/Hyperactivity Disorder (ADHD) mitigates responsibility often involve recourse to its genetic and neurodevelopmental etiology. For such arguments, individuals with ADHD have diminished self-control, and hence do not fully satisfy the control condition for responsibility, when there is a genetic or neurodevelopmental etiology for this diminished capacity. In this article, I argue that the role of genetic and neurobiological explanations has been overstated in evaluations of responsibility. While ADHD has genetic and neurobiological causes, rather than embrace the essentialistic notion that it directly diminishes selfcontrol and, therefore, responsibility, we ought to think of ADHD as constraining only some self-control practices. In particular, situational self-control strategies remain feasible for people with ADHD. However, not all individuals have access to these strategies. I suggest a way to evaluate responsibility in terms of situational rather than agential pleas, which tracks whether the individual had access to self-control behaviors. While I restrict my discussion to ADHD, the access-based approach is also relevant for assessments of responsibility for other cases where self-control failures are at stake.
\end{abstract}

Keywords ADHD · Responsibility · Moral responsibility · Self-control · Genetic essentialism

P. Koi $(\bowtie)$

Polaris Koi, University of Turku, Turku, Finland

e-mail: polaris.koi@utu.fi

\section{Introduction}

Attention Deficit/Hyperactivity Disorder (ADHD) is often $^{1}$ seen as decreasing the degree to which one can be held responsible. ${ }^{2}$ A standard conception of moral responsibility holds that it involves a control condition, i.e., that agents can only be held responsible to the extent that they were in control of their behavior. The responsibility of persons with ADHD is mitigated, it seems, because genetic and neurodevelopmental causes have contributed to their having a diminished capacity for self-control, thereby undermining the extent to which these agents are in control of their behavior. As a result, agents with ADHD sometimes act and cognize in ways that they do not fully control.

It seems that individuals with ADHD sometimes fail in responding adequately to reasons simply due to their struggles with self-control. This notion is also embraced by critics of the standard conception, such as Nomy Arpaly [6, 7], who illustrates this with the story of John, an adult with Attention Deficit/Hyperactivity Disorder

\footnotetext{
${ }^{1}$ For views arguing that ADHD should be a mitigating factor, e.g., in criminal sentencing, See [1]. For research on lay thinking about ADHD and responsibility, see [2-4].

${ }^{2}$ Recent debate has highlighted the ambiguity of the concept of responsibility. In this paper, the focus is on what Shoemaker terms the accountability sense of responsibility [5], which is compatible with both the standard conception of responsibility and reactive attitudesbased accounts. An agent is accountability-responsible for $\mathrm{x}$ when she has acted in such a way that it is appropriate for us to blame or praise her for so acting. In what follows, unless stated otherwise, 'responsible' refers to the accountability sort of responsibility, and 'blame' refers to blame warranted by these actions. Accountability-blame is gradated: blame may be mitigated, or the agent may be wholly excused.
} 
(ADHD). John, upon seeing an attractive house from his car, buys it within minutes. In making this purchase, he does not consult his wife, despite that they were not looking to buy a house. His impulsive purchase causes financial distress to his family and is an act on grounds of which we would ordinarily find it appropriate to blame him.

If John were normal - that is, if we could assume that in John, the same relationship between urge and action holds as in an ordinary person - his behavior, especially his failure to consult his wife, would indicate moral indifference to us. However, John's neurological disorder results in an astounding loss of selfcontrol - however much he wants to, he simply does not have, in some circumstances, the ability to stop before acting, think, and implement his practical conclusion. [6:22.]

Arpaly then argues that John is not an appropriate target for blame because due to his disorder, the buying of the house is not a sign of moral indifference or ill will. For Arpaly's account, the agent is excused or blame is mitigated due to features of the individual agent - not because they infringe on the control condition, but rather, because they indicate that the agent's behavior may not be an accurate reflection of their quality of will [6: 21]. For John, that feature is his self-control impairment. John has behaved in a reckless manner in making such a major purchase without consulting his wife or the state of family finances. Arpaly suggests that upon learning about "the fact that John has no self-control [...] given his organic deficiency of self-control" [7: 152], we accept that John's failure to engage in these activities was not due to moral indifference and conclude that John is not to be held (fully) responsible for his purchase.

Pleas for excusing or mitigating responsibility can be divided into two rough groups. Let us label these situational pleas and agential pleas. Situational pleas excuse the agent by appeal to a feature of the situation that limited the agent's capability to control their behavior in accordance with our moral demands, such as that they were misinformed about what they were doing, were strong-armed into it, or were tied to a chair. Agential pleas excuse the agent by characterizing the agent as not fully capable of moral behavior, in that the agent is, in Strawson's [8] words, "warped or deranged, neurotic or just a child". In such a case, the person's agency is either not fully developed, or is limited, either globally or locally, ${ }^{3}$ by a biological condition beyond the agent's control. The mitigating or excusing factor is not a feature of the situation the agent was in, but rather, a feature of the agent. As long as that feature remains stable, the agent is considered less than fully responsible and may be considered to be outside the moral community. ${ }^{4}$

When genetic and neurobiological explanations apply to an agent's atypical behavior, agential pleas are often invoked. ${ }^{5}$ An agential plea is also what Arpaly appears to have in mind for John ${ }^{6}$ : due to genes, neurobiology, or other inexorable features of his person (that we associate with his ADHD), John is simply uncapable of self-control in the face of the house he fancies. When Arpaly writes, "His lack of self-control exempts him from blame (if we assume that he has not, for example, knowingly refused to take his medication)" [6:21], she seems to suggest that due to John's trait - his selfcontrol impairment - we assess him as less than fully responsible, and the genetic and neurobiological explanations of that trait are seen as supporting the idea that his poor self-control is indeed a relatively stable trait of the agent. Medication is seen as 'canceling out' some, but not all, of the behavioral effects of these traits.

\footnotetext{
${ }^{3}$ Global agential pleas are such as are applied, e.g., to toddlers who are not held to be full agents in the relevant sense with respect to any behavior, and are placed outside the moral community: a helpful discussion of disabled agents who may fall just inside or just outside the moral community is provided by Shoemaker [5]. Local agential pleas are such as Arpaly applies to John: since behavior caused by John's poor self-control is taken to not reflect poorly on his quality of will, John is excused for behavior caused by a failure of self-control, but not for other behavior.

${ }^{4}$ All behavior, of course, is done by individuals in situations. There is no metaphysical bright line between agential and situational pleas. Rather, this is a pragmatic distinction meant to characterize most appeals to mitigate or excuse responsibility.

5 This phenomenon is further characterized in sections 2 and 3.

${ }^{6}$ In the passage quoted above, Arpaly does qualify John's incapacity to "some circumstances". Is this to be interpreted as suggesting that something like situational pleas is to be intended, after all? I think that an unlikely reading, given the repeated emphasis Arpaly places on her characterization of John as persistently, biologically abnormal. Rather, the qualification can be interpreted as acknowledging that John sometimes succeeds in self-control out of luck. Arpaly [7:151-153] draws an analogy to someone with Tourette's syndrome who says "fuckers!" in a family gathering. Of course, someone with coprolalia (a relatively rare vocal tic, present in a minority of Tourette's patients) will not always utter obscenities. But the uttering of obscenities, for Arpaly, is not something the patient can control. The coprolalic patient is not to be blamed for saying "fuckers!" any more than he is to be praised for not doing so, because neither reflects on the patient's quality of will. Likewise, on Arpaly's analysis, for self-control impairments in ADHD.
} 
As I will argue, medication is not the only agentexternal factor that significantly contributes to selfcontrol successes and failures in persons with ADHD. In addition to genetic, neurobiological and medical factors, many social, educational, psychological, and environmental phenomena can act as constituents of selfcontrol (or lack thereof). Self-control is a broad construct encompassing a wide range of behaviors, only some of which are made significantly harder by ADHD. Whether the individual's circumstances facilitate self-control for that person will vary on a situational basis. This is doubly important for persons whose self-control is particularly vulnerable to environmental variance, such as persons with ADHD, for whom the management of their disorder involves finding situational strategies to support their self-control and avoiding environmental factors that may undermine it. As a result, I argue that situational pleas ought to be preferred to agential pleas when discussing moral and criminal responsibility for failures of self-control, including in persons with ADHD.

In order to analyze how it is that ADHD impacts one's capacity for self-control and, hence, responsibility, I also discuss two other themes, addressing which is helpful for resolving the question at hand and for making my case in favor of situational pleas. First, what sort of role should explanations involving recourse to the genetic etiology of ADHD play in assessing their responsibility? Second, how should self-control be understood in order to effectively assess whether, and to what degree their responsibility ought to be mitigated? I argue that in the context of responsibility assessments, the genetic and neurodevelopmental etiology of ADHD does not show that agential pleas would be appropriate in the context of self-control impairments. Rather, they highlight a need for an account of self-control that describes it in terms of access to behaviors, where selfcontrol is generated in interaction with the environment. An access-based approach enables assessing and mitigating responsibility in a way that is sensitive to the heterogeneity among people with ADHD and the context-dependence of such assessments diachronically for the same individual. As I will try to show, situational pleas are best suited for this task.

This paper will proceed as follows. An overview of ADHD and the current debate on its impact on responsibility is provided in section 2 , while section 3 expands on that debate with particular attention on how our thinking about genes and brains shapes our responses towards ADHD. In section 4, I describe an externalist stance on self-control, arguing that self-control failures are best explained in externalist terms. The heart of the present paper can be found in section 5, which brings together the preceding discussions of ADHD, responsibility, and self-control, describing how it is that individuals with ADHD are at a disadvantage with regard to self-control and how it is that the situation could be amended.

\section{ADHD and Responsibility}

ADHD is often described as the most common childhood neurobehavioral disorder. It is typically diagnosed in childhood or adolescence, although the diagnostic criteria have recently been updated to better accommodate diagnosis in adulthood [9]. Persons with ADHD struggle with behavioral and attentional control. They may act impulsively, have trouble actively listening to instructions or feedback, or have trouble planning for the future. As a result, persons with ADHD are often described in normatively loaded terms: as problem children and reckless teenagers $[2,3,10]$. These persons are often held to be less responsible for their misbehavior due to their ADHD. Not only do others excuse individuals on grounds of their ADHD, individuals with ADHD also externalize problematic behaviors to their ADHD, which can help alleviate feelings of guilt or self-blame [11, 12].

DSM-V lists eighteen core symptoms of ADHD which are divided into the subgroups of inattention and hyperactivity-impulsivity. The two symptom dimensions are distinct but correlated. Examples of inattentive symptoms include trouble holding attention on a task, trouble completing a task, forgetfulness in daily activities, and losing items necessary for tasks and activities. Examples of hyperactive-impulsive symptoms include motor fidgeting, excessive talking, trouble waiting for one's turn, and frequent interrupting or intruding on others. [9].

The symptoms of ADHD correspond to impairments in various dimensions of self-control, such as inhibitory control, delayed gratification, and temporal discounting. As a result, Barkley [13] has characterized ADHD as a disorder of self-control. ${ }^{7}$ For Barkley [13, 14], a neurodevelopmental impairment of the executive

\footnotetext{
${ }^{7}$ I take for granted that difficulties in self-control are a crucial aspect of ADHD but remain agnostic about whether ADHD is reducible to impaired self-control.
} 
functions causes the persistent self-control difficulties characteristic of ADHD. When the disorder is seen as (neuro)biological and genetic, it is often also seen as an exculpating or mitigating influence on the individual's behavior: we cannot help the way we are born.

ADHD was formerly believed to be a transient childhood disorder, but we presently know that symptoms often persist into adulthood [14]. The most common clinical response to ADHD is stimulant medication, although other medications and behavioral interventions are also used for managing the disorder. Various etiologies for ADHD have been suggested, but most such suggestions, such as exposure to sugar or poor parenting, have not been substantiated. The consensus is that ADHD is a highly heritable neurodevelopmental disorder, and that while the environment has an impact on it, social factors alone cannot bring about ADHD. While the heritability of ADHD has long been estimated to be at roughly $70-80 \%$ based on decades of twin studies [15], specific risk genes for ADHD were first identified very recently, in a genome-wide association study published in Nature Genetics [16]. The study found twelve risk loci for $\mathrm{ADHD}$, and furthermore noted that the loci were in concordance not just with whether or not an individual was diagnosed with ADHD but also with a spectrum of subclinical ADHD symptoms, supporting the idea that ADHD and subclinical impairments in selfcontrol and related behaviors lie on a continuum [15, $16]$.

ADHD is also associated with differences in neurobiology. These differences are connected with impairments in the executive functions [13, 14], as documented using both EF scales and EF tests. ${ }^{8}$ The pathophysiology of $\mathrm{ADHD}^{9}$ is by no means homogenous: each physiological correlate of ADHD may be relevant only

\footnotetext{
${ }^{8}$ Executive functioning deficits are characteristic of both children and adults with ADHD, although they are subject to individual variance. Out of the executive functions, poor performance in planning and inhibitory control tasks is common, but not ubiquitous, in subjects with ADHD; deficits in working memory appear more prevalent [14].

${ }^{9}$ Functional neuroimaging studies support the idea that ADHD relates to impaired executive functioning: a meta-analysis relating FMRI studies to the seven large-scale brain circuits found hypoactivation in the frontoparietal network, involved in executive functioning, in both children and adults with ADHD [17]. By contrast, hyperactivation was observed in both children and adults in the default network, which underlies processes that are not focused on the outside world, such as self-referential processes, planning and daydreaming (ibid.) Structural neuroimaging studies have furthermore found ADHD to correlate with differences in gray matter volume in various areas of the brain, including the basal ganglia and occipital lobes; stimulant medication is associated with the normalization of these structural differences (ibid.).
}

to a subset of persons with ADHD. Neuroimaging is not a plausible substitute for clinical interview in diagnosis. However, while the differences in brain anatomy and functioning in persons with ADHD compared to controls are varied, they are consistent with the clinical and behavioral finding that differences in executive functioning are characteristic of ADHD.

The self-control of individuals with ADHD is subject to individual variance. Some individuals with ADHD seem to succeed in tasks, careers and projects that place robust demands on their self-control, ${ }^{10}$ lending support to portrayals of ADHD as a strength. Such success stories can be motivational for many people with ADHD and their loved ones, who wonder about how their diagnosis will impact their life. Yet while these success stories highlight that persons with ADHD lead a variety of lives, a one-sided description of ADHD as a strength can feel like erasure for persons whose relationship with their ADHD is an uphill battle.

Many adults with ADHD face considerable difficulty in the educational, occupational, dating and marital and financial spheres [14]. Barkley describes the adverse effects of ADHD on educational achievement as "chronic and cumulative" (ibid., p. 314), and reports a correlation between ADHD and lower work performance (ibid.). Fiscally, adults with ADHD are more likely than controls to face challenges in managing their finances, such as, to engage in impulsive shopping, to have trouble paying rent and bills on time (ibid.) Barkley also draws attention to an aspect of ADHD that has received less attention: its impact on social functioning, such as in the context of relationships. Barkley notes that the impairments in top-down inhibitory control that are a central feature of ADHD also extend into the domain of emotional regulation, and that impaired emotional self-control commonly manifests in "temper outbursts and more unstable personal relationships; and [...] difficulty maintaining friendships" (ibid., 327).

For persons facing struggles described above, ADHD may feel like a persistent handicap where their impaired

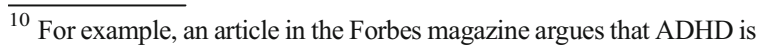
"an entrepreneur's superpower" [18]. The portrayal is based on the observation that some extremely professionally successful individuals, such as some celebrities, have ADHD, and on the postulation that this success is due to these individuals' symptoms, which in the right context turn to strengths. That some individuals with ADHD outperform others, e.g. in terms of educational achievement, is also noted in the academic literature [11]; it has been suggested that this is representative of compensation for the impairment related to ADHD rather than less severe symptoms.
} 
self-control adversely impacts their capacity to function in multiple areas of life, from work to relationships. Yet while adults with ADHD are more likely than controls to face adversity in all these domains of functioning, some individuals with ADHD experience these challenges to a significantly smaller extent. There appears to be considerable variance in how, and to what extent, the self-control of persons with ADHD is impaired. An account of how responsibility should be assessed and mitigated in persons with ADHD should be able to account for this variance.

In addition, there is documented variance in the selfreports of individuals with ADHD assessing their own capacity for responsibility and to what extent it has been impaired by ADHD (see, e.g., 5, 2, 12]. Individuals with ADHD are often seen as, or experience themselves as, having trouble following their own normative convictions as well as the moral codes of society $[1-3,19]$. One aim for medical interventions for ADHD, then, is the restoration of moral agency. Based on research by Ilina Singh [2, 3], there is some indication that this aim is realized: Singh analyses an interview study of 151 children with ADHD in the UK and US, where the children's self-reports suggested that in the children's own experience, "stimulant drugs enable, rather than threaten, moral reasoning in the face of conflicting impulses" [3] - although the overall efficacy of common stimulant medications, such as methylphenidate, continues to be debated [20].

ADHD can result in grave impairments in an individual's self-esteem, social and occupational life [14, 21]. It is furthermore a risk factor for criminal activity, drug and alcohol abuse disorders, anxiety and depression $[1,21]$. While appeals to ADHD in courtrooms are uncommon and successful appeals even more so, individuals with ADHD are overrepresented in the criminal justice system [22]. International studies show that up to half of the adult prison population, and two thirds of juvenile offenders, screen positive for childhood ADHD. Many continue to be symptomatic [21].

\section{Genes, Brains, and Agential Pleas}

Within academic debates surrounding criminal responsibility, discussions around the moral and criminal responsibility of people with ADHD often propose a neural and genetic etiology and ontology of ADHD. Robert Eme [1], for example, argues that ADHD ought to be treated as a mitigating factor in criminal sentencing, because "the diminished capacity for self-control in ADHD is caused (at least in part) by a dysfunction in the [dual systems]. [...] in the case of ADHD [...] the dysfunction is due primarily to genetic factors" (ibid., 352-353). That is, ADHD entails a dysfunction on the level of systems neuroscience, a dysfunction that is genetically caused, and is an exculpating or mitigating factor because of its biological etiology and ontology: we cannot help the way we are born. ${ }^{11}$

Nita Farahany [23] calls such stances as Eme's 'behavioral morality'. On the behavioral moralist view as described by Farahany, biological causes of behavior are exculpating or mitigating factors for criminal sentencing because they render individual behavior less subject to volition. According to such views, the agent's behavior fails to reflect their volition in ways that matter for ascriptions of responsibility due to being determined, either partially or wholly, by their biology. Behavioral moralist views are, in essence, agential pleas. They involve the stipulation that some features of the individual - in this case, individual biology - prevent that individual from being a fully-fledged moral agent.

However, as Farahany notes, it is very hard to make direct inferences from evidence in brain physiology to evaluations of individual responsibility. Neuroscience and related disciplines work in a way that is often both more basic and more general than the sort of information that could, in practice, inform assessments of the physiology of specific behavioral causation for individual moral agents in the relevant ways [23]. As a result, individual behavior cannot be neatly divided into behaviors resulting from biological causes, such as genes or atypical neural functioning, on one hand and social causes and/or full-fledged agency on the other. Rather, the empirical question in the study of behavior is to find out how biology and the environment together shape individual agency.

In a study by Lebowitz, Rosenthal \& Ahn [4], lay responses toward the behavior of children with ADHD were gauged using vignettes that attributed their behavior either to biological or to psychosocial causes. Attribution to biological causes, such as genetics, decreased attributions of both blame and control, and diminished

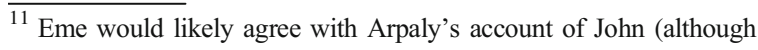
note that Arpaly takes no stance as to whether John's lack of selfcontrol is biologically caused or constituted, simply stating that it is biological in character).
} 
stigmatizing attitudes towards these children. But it also prompted perceptions of ADHD as relatively untreatable. This effect has been called 'the doubleedged sword' and has also been noticed in other contexts assessing genetic explanations of agency. For example, genetic accounts of criminality reduce perception of the perpetrator's control and ascriptions of blame, but they also prompt perceptions of this behavior as characteristic and expectations that the perpetrator will reoffend [24-26]. In short, genetic explanations result in perceptions of the moral responsibility of persons with ADHD on agential rather than situational terms.

This double-edged sword is often termed 'genetic essentialism'. The term 'genetic essentialism' refers to a set of cognitive biases related to interpreting genetic information about the causation of behavior. DarNimrod \& Heine describe the phenomenon as follows:

Learning about genetic attributions for various human conditions leads to a particular set of thoughts regarding those conditions: they are more likely to be perceived as (a) immutable and determined, (b) having a specific etiology, (c) homogeneous and discrete, and (d) natural, which can lead to the naturalistic fallacy. [27: 800.]

All these notions demonstrably arise in response to information about the genetic causes of specific behaviors. Dar-Nimrod \& Heine use the concept of essence placeholder to describe lay attitudes towards genetics: genes are assigned placeholder status with respect to a person's immutable core traits. In this view, genetic determinism - the view that genes direct behavior in a way that undermines genuine agency - is an aspect of genetic essentialism [27]. ${ }^{12}$

The reality of genetic causation of behavior is far from the stark effect that postulated genetic explanations have on lay ideas of responsibility. Some traits are indeed produced by specific, discrete genes. This is true, e.g., for some genetic diseases. However, the vast majority of phenotypes are produced by multiple genetic and gene-environment influences [19,28]. Following behavior geneticist Eric Turkheimer [19], the prospects of any project matching behavioral phenotypes with discrete genes are gloomy. While behavioral traits, in general, are heritable - some more so than others - the

\footnotetext{
${ }^{12}$ See [26] for a view distinguishing the effects of genetic determinism from those of genetic essentialism.
}

relationship of behavioral phenotypes to genes is many to many, not one to one. Likewise, the causal pathways leading to these phenotypes involve complex gene-gene and gene-environment interactions in addition to environmental causes. As Dar-Nimrod \& Heine [27] remark, the more complex the genotype-phenotype relationship, the less rational a genetic essentialist response appears. As a result, despite the widespread association of genetic explanations with agential pleas, agential pleas are not supported by empirical evidence in behavioral genetics.

Finally, a tendency towards agential pleas has also been documented in qualitative research. Honkasilta, Vehmas \& Vehkakoski [12] have documented that ambivalence is present in the narratives of individuals with ADHD about their moral agency: individuals with ADHD sometimes use the label to externalize or excuse misbehavior whereas sometimes, they assert that ADHD does not hinder their agency or self-control, committing themselves to norms of behavior and holding themselves responsible for any failures to follow those norms (ibid.).

This ambivalence reflects a difficulty in agential pleas: while they may enable us to excuse agents in situations where they ought to be excused, they also carry with themselves the baggage of describing the agent as persistently incapable of full-fledged agency. Because ADHD is persistent, any associated diminishment of self-control is often assumed persistent. The qualitative research reflects that agents who may have acted in wayward ways due to self-control failures that are associated with their ADHD may prefer assuming responsibility to describing themselves as less than full moral agents. In these dilemmas, the third option - the situational plea - appears obscured by a focus on the persistence of the agent's ADHD. I hypothesize that these agents may assume that when behavior is explained by reference to a persistent trait, to admit to a failure of control is to admit to a persistent failure of control. Agential pleas may thus seem as if they were the only sort of plea available. Yet if self-control (or lack thereof) is subject to situational variance, situational pleas regarding moral and criminal responsibility become a salient option.

Consider responsibility mitigation for agents like John, bearing in mind that the self-control difficulties experienced by people with ADHD are variable not just from one individual to another but also diachronically within the same person, from one situation to another. Because his impulsive real estate purchase seems 
extreme to us, the example may lead us unduly towards thinking that John is entirely uncapable of self-control. Yet it is plausible that John frequently does things that most would find rather more demanding on their selfcontrol: he might, e.g., mow the lawn on a hot day, refrain from shouting at his children when he finds them sneaking to the cookie jar way past bedtime, and hold his tongue when his boss assigns him to a client he despises. An agential plea based on John's real estate impulsivity runs the risk of not assigning John due responsibility for the many other things he does. Yet an assessment of John's responsibility scaled to his success in other tasks would run the risk of also holding him fully responsible for his self-control failure in the real estate purchase. Situational pleas would be best suited to properly dealing with this heterogeneity.

In summary, neither neuroscience nor behavior genetics support agential pleas over situational pleas. While both are powerful methods of scientific inquiry, their applicability to the assessment of individual epistemic or moral responsibility is limited. Ideas about the immutability of self-control in persons with ADHD may stem from genetic essentialist and behavioral moralist thinking that is at best a misunderstanding of the science. This is not to dispute that disorders like ADHD are grounds for special considerations when it comes to self-control. But as I will argue below, because our social and environmental arrangements currently do an erratic job at enabling people to enact self-control, those considerations are better employed as situational pleas.

\section{The Environment in Self-Control}

Due to its genetic etiology, ADHD has been seen as a fairly immutable trait, although symptoms often decrease in severity as the subject matures [14]. Ascriptions of responsibility for people with ADHD have been attached to their ADHD. An agential plea, such as given by the behavioral moralist, would scale the mitigation of responsibility to the degree of the relevant impairment. In such an account, the more severe a person's ADHD, and the more their self-control is compromised, the more their responsibility is mitigated. For the behavioral moralist, successful medication decreases the severity of ADHD, restoring responsibility.

Situational pleas present themselves as a viable alternative to agential pleas in the case of ADHD if we remark how our responsibility assessments do not seem to be mitigated just with respect to diagnoses, genetics, or persistent neurobiological traits. They seem to be mitigated (or aggravated) also with respect to the way the environment constrains and scaffolds agency, such as with respect to how these traits are managed. Yet allowing that properly managing an innate trait, e.g., with medication, is relevant for assessments of responsibility is only part of the equation.

Arpaly is right that insofar as responsibility is compromised in particular ways for persons with ADHD, it is due to the difficulties they have with self-control. Selfcontrol, however, is a heterogeneous construct under much current debate in both philosophy and the empirical sciences. In philosophy as well as in ordinary parlance, self-control refers, broadly, to the capacity to align behavior with intentions and better judgment. Within psychology and related disciplines, it is operationalized in various ways, most commonly as trait selfcontrol, inhibitory control, delayed gratification, and temporal discounting. These constructs are distinct yet interrelated and consistent [29, 30]. The heterogeneity of various processes and behaviors associated with selfcontrol suggests that self-control is not a natural kind [31].

The idea that self-control is not fully agent-internal is not novel to the present paper. Neil Levy [32, 33] has persuasively argued that rather than being a display of an innate capacity for inhibitory control, self-control makes use of various environmental practices. For example, someone striving to diet avoids the street where the bakery is, thus keeping clear from the delicious smell of baked goods. In Levy's analysis, multiple experiments have demonstrated that persons high in trait self-control or in delayed gratification do not necessarily employ inhibitory control, but rather, either avoid environments where behavioral inhibition is required or modulate their interaction with those environments. An example of such research is Mischel's [34] famous 'marshmallow test'. In the experiment, children were instructed to wait for the researcher in a room with an edible treat, such as a marshmallow, without consuming it; if they succeeded, they got two treats instead of one. In this experiment (and subsequent variants), the children who succeeded in not eating the marshmallow appeared to do so not by means of iron inhibition but rather by directing their attention elsewhere, such as by singing, turning their back to the marshmallow, imagining the marshmallow is a tiny cloud, or attempting to fall asleep. Mischel and colleagues [35] furthermore 
found that these heterogeneous behaviors that helped children succeed in not eating the marshmallow are teachable.

Mischel et al.'s research suggests that the role of the environment in the production of self-control is not merely something where the individual takes a passive role. Individuals consciously shape and choose their surroundings, and how they relate to these surroundings, in order to be more self-controlled. Duckworth, Gendler \& Gross [36] argue that situational strategies of self-control are not just a complement to what they term intrapsychic strategies of self-control: based on their research, situational strategies are the more potent means for self-control because they can be used to diffuse an oncoming impulse before the impulse gets too strong.

Not only does the environment figure in situational strategies of self-control, intrapsychic strategies, such as rehearsing one's reasons for doing what one judges best, or construing of the marshmallow as a tiny cloud, often also depend on the environment in various ways. For example, intrapsychic strategies can be learned and taught, and they are subject to interference from external distractions.

In addition to strategies of self-control, self-control can manifest in seemingly mechanistic ways. For example, an agent may be presented with an impulse, e.g., to yell at a child, but simply inhibit that impulse without (conscious) recourse to any internal strategy. As a result, there is a wide range of behaviors, including mechanisms as well as strategies and practices, that we label self-control because of their function rather than their structure.

Which behavior or behaviors of self-control are employed in a given instance of self-control depends on the individual at hand and their immediate and past environment. The individual's genes, neurobiology, and personal interests and preferences play a role in what strategy or mechanism of self-control to employ. Past environment has a shaping role in what sorts of selfcontrol practices and behaviors the individual has learned; the immediate environment regulates what sorts of self-control practices are currently available. For example, a prisoner is unable to simply walk away when a fellow inmate begins to heckle them, removing one selfcontrol behavior that is available to most others upon noticing an impulse towards aggressive behavior.

On the other hand, environments can enable behaviors of self-control otherwise unavailable. Ulysses arrangements, where an agent enables refraining from a given activity by physically preventing it are a good example of practices of self-control that environments facilitate. For example, a student wishing to stay off social media in order to get a paper written might install an application that prevents them from accessing certain websites and applications for a given period. In an environment where such applications would be in standard usage much like the most common word processors are, the environment would not just enable but foster and encourage such self-control behaviors. Environments can support or undermine responsibility by virtue of their impact on self-control.

The heterogeneity of self-control behaviors shows that self-control is multiply realizable. Persons who have aggressive impulses upon being heckled refrain from aggressive behavior and procrastinators coax themselves to write papers all the time, but how they accomplish such instances of self-control varies tremendously, ranging from simply inhibiting conflicting impulses without much thought to it, to rehearsing one's reasons to act in a preferred way, to walking away or establishing Ulysses arrangements. In assessing the responsibility of persons with ADHD, our question then becomes whether, and in what sorts of situations, persons with ADHD can realize self-control behaviors. In the following section, I will argue ADHD does not directly decrease self-control. Rather, due to it, certain self-control behaviors may become impossible or difficult to enact. However, due to the tremendous heterogeneity of self-control behaviors, other strategies remain available to persons with ADHD if those can be accessed in a given situation. Compare this idea to another capability, the capability to make music. Various illnesses and physical trauma may impair an individual's ability to sing, but that does not mean they would be prevented from making music as they could also play an instrument - at least if the individual can access instruments and instruction, is not prevented from practicing, and so forth. While these two capabilities are not perfectly analogous, they are alike in that both are subject to multiple realizability and situation-sensitivity. Due to the multiple realizability and situation-sensitivity of self-control, an inference directly from the presence of a genetic condition such as ADHD to responsibility mitigation is mistaken. Rather, responsibility ought to be mitigated or the agent excused only in situations where self-control behaviors were not accessible for the agent. 
The reader may here object that given the heritability of ADHD, even if situational strategies are an important aspect of self-control, they are not what is at stake for persons with ADHD: persons with ADHD have impaired self-control because of their genes or because of their neurobiology, not because of their environment. After all, they share their environments with persons who do not have impaired self-control. This objection merits a response before proceeding.

It is true that the robust role of the environment in self-control behaviors may appear contradictory to what we know about disorders like ADHD. The strong heritability of ADHD gives rise to various intuitions about it being immutable, and it is deceptively easy to extend the same immutability to self-control impairments associated with ADHD. However, these intuitions do not match what we know about the genetic causation of complex behavior. Instead, findings in behavior genetics support thinking about self-control in persons with ADHD as involving environmental causes and as including situational strategies of self-control.

Decades of twin studies have produced heritability estimates for ADHD at roughly 70-80\% [15]. that entails that $20-30 \%$ of variance is explained by geneindependent environmental factors. Heritability estimates however include gene-environment interactions. Gene-environment interactions are often thought of in passive terms [37]: a genotype, when placed in an environment, produces a trait in a way that responds to that environment. However, gene by environment interactions (GxE for short) can also be active. Passive geneenvironment interaction refers to how genes code for how the individual organism responds to specific environmental influences, but individuals also actively seek out and create environments that are a "good fit" for their genotype, which is referred to as active GxE. In other words, while GxE interactions encompass such 'passive' interactions as epigenetic transmission in utero, some such interactions are not beyond the individual's control. Agents can select environments that foster desirable behaviors. GxE interactions are an important form of genetic causation, and active GxE interactions are a form that agents participate in. Even as genes code for our traits, the way we select, shape and navigate our environments also has a role in the production of those traits [37, 38].

The genotype of persons with ADHD codes for differences in their self-control [15]. But that should not be interpreted in essentialist terms: the evidence does not indicate that self-control, in people with ADHD or otherwise, would be any more inherent or immutable than any other complex heritable trait is. Above, we saw that the environment has a robust role in the constitution of self-control. This is also true for self-control in persons with ADHD. The complex etiology of self-control impairments in ADHD does not foreclose externalism about self-control. On the contrary, findings in behavioral genetics about the genetic production of complex behavioral phenotypes lend support to highlighting the role of the environment in it. Of course, the behavior of people with ADHD is partly explainable by their genes and brains, in addition to their environments. But since this is a trivial fact in that it pertains to all human behavior, it is not particularly useful for probing whether and how people with ADHD ought to be held responsible.

Situational pleas are appropriate for self-control failures in ADHD because even as ADHD may be persistent, self-control failures are not a stable feature of the agent. Rather, as discussed in more detail in section 5 , agents with ADHD are perfectly capable of a wide range of self-control practices, unless those practices are prevented by a situation-dependent lack of feasibility or awareness. In assessing whether the agent ought to be excused for her self-control failure, we ultimately need to assess whether self-control behaviors were accessible for the agent in that situation. While genetic and neurobiological information can help highlight how not all self-control strategies are equally effective for all agents, taken alone it is of limited value in assessing to what extent agents with ADHD ought to be held responsible.

\section{Is Self-Control Accessible for Persons with ADHD?}

Above, we have seen that the environment has a robust role in self-control behaviors, but the argument for why that entails that pleas for mitigating moral responsibility for persons with ADHD should be situational pleas remains to be made. In a nutshell, that argument is as follows: persons with ADHD have impoverished access to self-control behaviors. This is because an environment that adequately fosters self-control for persons without the disorder does not foster it to the same extent for persons with ADHD. Not only may an environment that fosters self-control for someone without ADHD fail to do so for someone with ADHD, an environment that is harmless for the self-control of someone without 
ADHD may severely undermine the self-control of someone with the disorder. For this reason, situational pleas are available for persons with ADHD even in contexts where they are not available for persons without the disorder.

As discussed above, there is convergent evidence that persons with ADHD have different executive functioning when compared to controls. Due to these differences, persons with ADHD are more likely to have difficulty enacting behaviors strongly reliant on executive functioning. Many self-control behaviors, such as that of inhibiting a prepotent impulse by intrapsychic or mechanistic means, are prime examples of behaviors firmly dependent on the executive functions. However, it must be borne in mind that many self-control behaviors crucially involve the environment.

Interactions between the genetics and neurobiology of persons with ADHD and their environments in the production of self-control behaviors take varied forms. For persons with ADHD, their different neurobiology yields special considerations as to what sort of selfcontrol behaviors they can enact. Explaining differences in self-control in terms of access to self-control may help solve the mystery of heterogeneity in the extent to which individuals with ADHD succeed in self-control. Based on the above empirical evidence, it is highly plausible that some individuals with ADHD have better access to self-control behaviors than others; and it is also plausible that it is easier to access such behaviors in some situations than it is in others.

Environmental factors that have been used to foster self-control in persons with ADHD include environmental self-control arrangements, such as arranging for frequent feedback, increased monitoring, and Ulysses arrangements where the action to be avoided is made physically unavailable, and medication. However, not all individuals live in environments that they can readily structure in order to use them for self-control purposes. Feedback and monitoring are likewise not available for everyone or everywhere. This uneven availability also pertains to medication, which is not always available to individuals with ADHD, whether due to the medication not being suited to this individual due to side effects, financial reasons, a parental decision not to medicate, or a lack of information. Individuals with ADHD vary greatly in terms of to what extent they can access any of the abovementioned sorts of environmental selfcontrol support: for example, Ulysses arrangements may be easier to arrange when there is financial flexibility. Furthermore, the extent to which individuals with ADHD can access such environmental self-control supports varies from one situation to another. For example, Ulysses arrangements may be more available at home than they are at school or workplace contexts.

In the absence of available self-control behaviors, individuals with ADHD may act in ways that result in prudential and moral failures. They may act impulsively, or fail to implement their chosen course of action and procrastinate. In assessing whether the individual ought to be held fully responsible for these failures, or whether excusing the individual or mitigating responsibility is appropriate, we ought to ask whether the individual had access to self-control behaviors. Arpaly [6: 23-24] gestures towards a similar concern. She remarks that while we may expect agents to take a deep breath and count to ten rather than give in to an outburst of rage, or to delete the games folder on their computers rather than give in to procrastination, sometimes such "“counting to ten' measures" - Arpaly's phrase for self-control strategies are not available. The access approach to self-control within this paper can be taken as building on that remark.

For a self-control behavior to be accessible for an individual, requires, at minimum, that the behavior is feasible and that the individual is aware of the availability and efficacy of this behavior. The latter, epistemic, constraint to self-control seems commonplace: information about the various ways in which self-control can be enacted is rarely available.

Despite the growing attention given to externalist strategies for self-control in the scientific literature, discussed above, these are often not being addressed in teaching self-control, whether at home or school. Both children and adults are often simply advised to "just (not) do it". Consider Laura, a little girl, who hits her younger brother. When her father scolds her for it, Laura breaks into tears, saying that she knows it's wrong to hit someone, but the brother was so annoying, she just couldn't help herself. "Even if it's hard, you need to control yourself", the father responds. This furnishes the individual with a further impetus to self-control in the form of social pressure yet is unhelpful in helping Laura understand how to enact self-control.

Situations like Laura's are a challenge for all children, yet children are typically expected to, over time, come up with their own behavioral strategies for selfcontrol. For children with ADHD, this process can be harder, take a longer time, and have less reliable results. 
Furthermore, situations where there is a social expectation for self-control success but no practical support is available can be considerably stressful for individuals with the disorder.

Some common approaches in education provide advice on how to succeed in self-control, but that advice is not always equally suited for everyone. For example, advice to students (and professors) struggling to write a paper often begins with the sage advice of (figuratively) gluing one's behind to a chair. While such advice can be helpful for some, for individuals with ADHD, advice focused on staying still and focused for prolonged periods of time can be markedly hard to follow. When alternative strategies are not taught, persons with ADHD are set at a disadvantage in terms of having salient strategies for self-control that they are able to enact.

In brief, even as our knowledge of how self-control behaviors are enacted is growing, it is not reflected in our practices as educators. ${ }^{13}$ While this impacts the quality of teaching self-control for all students, it has especially undesirable consequences for students with ADHD who may be less able to enact self-control behaviors without such overt advice.

In short, the way we teach self-control is often unhelpful and is it especially ill-suited to persons with disorders such as ADHD. As a result, in addition to barriers to self-control from the unavailability of self-control practices, epistemic barriers arise when individuals with ADHD are not aware of such self-control practices that would be suited for them. Access to self-control practices hinges on awareness and availability of such practices that one can enact.

Thinking of self-control in terms of access likens access to self-control behaviors to physical access. A wheelchair user is not inherently less able to get around, but the presence of environmental barriers significantly modulates their access to some spaces, and it modulates

\footnotetext{
${ }^{13}$ Information on how self-control is taught at school settings is scarce, even as educators often wish to impart self-control on their students. I consulted a textbook for educators wishing to teach their students beneficial character traits such as self-control and grit [39]. The textbook suggested mindfulness practice, giving students opportunities for making choices and facing the consequences, having students set goals and monitor their progress on those goals, and asking peers to remind each other to focus, each of these being recommended as a practice that is effective in teaching self-control (ibid.). These are all laudable practices, but they vary considerably in terms of the extent to which they effectively support the development of self-control. Notably, few of these methods make overt use of the environment, and none involve practical strategies in how to avoid or inhibit unwanted impulses.
}

that in ways that do not always prevent access to some spaces for all people. For example, for a wheelchair user to access a meeting room on the 3 rd floor, the building needs to have ramps and/or elevators, and the individual needs to be aware of their existence and of their location. Similarly for self-control in individuals with ADHD: while persons with ADHD are capable of many selfcontrol strategies and behaviors, there are significant environmental barriers that modulate whether a person with ADHD can enact self-control. In some situations, the epistemically and physically available self-control practices may not be suited for the different neural phenotype of persons with ADHD, resulting in an interaction with the environment that forecloses rather than enables self-control behaviors. By contrast, in other situations, individuals with ADHD may be either presented with self-control behaviors they can enact, or they may be able to actively change their environment in order to enable such behaviors. Much, if not all, of the individual variance in the self-control functioning of persons with ADHD can be explained by reference to active and passive environmental interactions.

Due to the genetic, neurobiological and behavioral heterogeneity of the disorder, we can expect there to be some variance in what environmental features best foster self-control for each individual with ADHD. Based on what we know about the range of biological and behavioral features of ADHD, however, it can be postulated that strategies relying heavily on the executive functions, such as on working memory and on inhibitory control mechanisms, are less successful for persons with ADHD. Environmental, situational strategies should be emphasized instead. Access to selfcontrol for persons with ADHD can be fostered by spreading awareness of and teaching environmental self-control strategies, and by encouraging environmental self-control practices in spaces where they are needed but presently often not allowed, such as schools and workplaces. These measures are useful beyond people with ADHD, as they also furnish people who have a hard time using executive functioning-heavy self-control strategies due to e.g. a poor night's sleep, a long day at work, or due to being tipsy, with strategies they too can enact; and, furthermore, they furnish everyone with methods of self-control that Duckworth, Gendler and Gross [36] suggest are more efficient than their executive functioning-heavy, intramental counterparts. 


\section{Conclusion: Situational Pleas Are best Suited for Failures of Self-Control}

In the beginning of this paper, I described lay and professional views that consider the genetic etiology of $\mathrm{ADHD}$, and its status as a neurobiological disorder, to inform responsibility assessments in a way that appears to support agential pleas. However, when we begin to appreciate the robust role of the environment for selfcontrol and the complexity of its biological causation, agential pleas turn out to be unhelpful.

I have argued that situational pleas are most appropriate for cases where responsibility is to be mitigated or the agent excused due to failures in self-control. Pleas to mitigate or excuse responsibility for agents with ADHD ought to be similar in structure to pleas that say the individual was strong-armed into it or was tied to a chair, rather than similar in structure to pleas that say the individual is partially outside the moral community due to their innate traits. This is because the trait on grounds of which epistemic and moral responsibility would be mitigated for individuals with ADHD is poor self-control. But the self-control in persons with ADHD is not inherently or immutably poor, nor is their selfcontrol difficulty any more 'biological' or 'organic' than that of any agent. Rather, they are at a disadvantage in accessing self-control behaviors. It is only in conjunction with environmental barriers to self-control that ADHD thwarts self-control success: the disorder itself is not sufficient for success in self-control to be prevented. Therefore, situational pleas have more explanatory force: accounting for responsibility in people with ADHD based on whether they have situational access to self-control practices explains heterogeneity in capacity responsibility between various individuals with ADHD as well as diachronic variation in selfcontrol for the same individual. In determining whether responsibility ought to be mitigated on grounds of selfcontrol failures, the presence of epistemic and practical barriers to self-control behaviors should be assessed. It should be determined whether the individual had full access to self-control in that situation.

Individuals with ADHD may be born with an inherited risk towards ADHD, but they are not born less capable of self-control nor less morally responsible. If the access theory of self-control is correct, their genotype simply modulates which self-control practices they can access - just as it does for people without the disorder. If there are no barriers to individuals' access to fitting self-control practices, ADHD need not impair self-control for that individual even if it does impact their executive functioning.

Self-control - the aligning of one's behavior with one's intentions and better judgment - is fundamentally a set of practices, not an innate trait. Innate traits, as well as environmental supports and constraints, modulate access to these practices. When assessing whether responsibility ought to be mitigated, instead of looking merely into the genotype or the brain, we ought to look into whether the individual had access to self-control practices.

While this article has focused on the case of ADHD, there is good reason to believe that the argument generalizes to any case where pleas for responsibility mitigation or exculpation are made on grounds of self-control failures. In such cases, we ought to direct our attention to whether the individual had access to self-control practices, keeping in mind that individual differences, such as neurodivergence, may modulate which self-control practices are feasible for the agent.

Returning now to Arpaly's $[6,7]$ description of John, I think John's failure in self-control is not just due to his neurological disorder. It is also due to environmental factors. Many such environmental factors are ones John can actively impact: unless epistemic or other barriers prevent it, John can set in place environmental supports and constraints that enable self-control, including Ulysses arrangements. If John indeed cannot enact selfcontrol upon coming across the beautiful house, it is not because of "the fact that John has no self-control [...] given his organic deficiency of self-control", as Arpaly puts it [7: 152]. Rather, it is because situational factors prevent him from enacting such practices that constitute that ability, such as Ulysses arrangements and other environmental strategies. This matters not only because it might turn out that John, despite his ADHD, could have indeed enacted self-control; it also matters because if John indeed was not able to enact any such strategies, that is plausibly caused in part by our societal failure to effectively and inclusively promote selfcontrol.

Put briefly, we do not respond differently to John because of any persistent trait of his, such as his ADHD, but because we assume there were no self-control practices he could have enacted in that situation. To assume that the former necessarily leads to the latter is to tread frightfully close to essentialism, and to overlook the importance of social and environmental structures for 
awareness and feasibility of self-control practices. Whether or not John had access to such practices should ultimately be the deciding factor in holding John responsible.

Acknowledgments This research has been funded by the John Templeton Foundation (via a Genetics and Human Agency research project Junior Investigator award) and by the Finnish Cultural Foundation. The author would like to thank participants in the Genetics and Human Agency research project, Kaisa Kärki, Juha Räikkä, and Jukka Varelius, as well as audiences at the European Society for Philosophy and Psychology and Association for the Advancement of Philosophy and Psychiatry annual meetings for helpful comments on earlier drafts of this paper.

Funding Information Open access funding provided by University of Turku (UTU) including Turku University Central Hospital.

Open Access This article is licensed under a Creative Commons Attribution 4.0 International License, which permits use, sharing, adaptation, distribution and reproduction in any medium or format, as long as you give appropriate credit to the original author(s) and the source, provide a link to the Creative Commons licence, and indicate if changes were made. The images or other third party material in this article are included in the article's Creative Commons licence, unless indicated otherwise in a credit line to the material. If material is not included in the article's Creative Commons licence and your intended use is not permitted by statutory regulation or exceeds the permitted use, you will need to obtain permission directly from the copyright holder. To view a copy of this licence, visit http://creativecommons.org/licenses/by/4.0/.

\section{References}

1. Eme, R. 2016. The neuroscience of ADHD, the paradigmatic disorder of self-control. Journal of Law and the Biosciences 3 (2): 350-354.

2. Singh, I. 2011. A disorder of anger and aggression: Children's perspectives on attention deficit/hyperactivity disorder in the UK. Social Science and Medicine 73: 889896.

3. Singh, I. 2013. Not robots: children's perspectives on authenticity, moral agency and stimulant drug treatments. Journal of Medical Ethics 39: 359-366.

4. Lebowitz, Rosenthal, and Ahn. 2016. Effects of biological versus psychosocial explanations on stigmatization of children with ADHD. Journal of Attention Disorders 20 (3): 240-250.

5. Shoemaker, D. 2009. Responsibility and disability. Metaphilosophy 40 (3-4): 438-461.

6. Arpaly, Nomy. 2006. Merit, meaning, and human bondage: An essay on free will. Princeton: Princeton University Press.

7. Arpaly, Nomy. 2003. Unprincipled virtue: An inquiry into moral agency. Oxford: Oxford University Press.
8. Strawson, P. 1962. Freedom and resentment. In Proceedings of the British Academy, volume 48: 1962, ed. G. Watson. Oxford: Oxford University Press.

9. American Psychiatric Association. 2013. Diagnostic and statistical manual of mental disorders. 5th ed. Arlington, VA: American Psychiatric Publishing.

10. Horton-Salway, M. 2011. Repertoires of ADHD in UK newspaper media. Health 15 (5): 533-549.

11. Fleischmann, A., and E.C. Miller. 2013. Online narratives by adults with ADHD who were diagnosed in adulthood. Learning Disability Quarterly 36 (1): 47-60.

12. Honkasilta, J., S. Vehmas, and T. Vehkakoski. 2016. Selfpathologizing, self-condemning, self-liberating: Youths' accounts of their ADHD-related behavior. Social Science \& Medicine 150: 248-255.

13. Barkley, R.A. 1997. ADHD and the nature of self-control. New York: Guilford Press.

14. Barkley, R.A. 2015. Attention-deficit hyperactivity disorder: A handbook for diagnosis and treatment. 4th ed. The Guilford Press.

15. Faraone, S.V., and H. Larsson. 2019. Genetics of attention deficit hyperactivity disorder. Molecular Psychiatry 34 (4): 562-575.

16. Demontis, D., R.K. Walters, [...] B. M. Neale (2019). Discovery of the first genome-wide significant risk loci for attention deficit/hyperactivity disorder. Nature Genetics 51 : 63-75.

17. Cortese, S., and F.X. Castellanos. 2015. Attention deficit/ hyperactivity disorder. In Neurobiology of brain disorders: Biological basis of neurological and psychiatric disorders, ed. M.J. Zigmond, L.P. Rowland, and J.T. Coyle. Cambridge, MA: Academic Press.

18. Archer, D. 2014. May 14. ADHD: The Entrepreneur's Superpower. Forbes Magazine Retrieved from https://www.forbes.com/sites/dalearcher/2014/05/14/adhdthe-entrepreneurs-superpower/.

19. Turkheimer, E. 2000. Three laws of behavior genetics and what they mean. Current Directions in Psychological Science 9 (5): 160-164.

20. Storebø, O.J., H.B. Krogh, E. Ramstad, C.R. Moreira-Maia, M. Holmskov, M. Skoog, T.D. Nilausen, F.L. Magnusson, M. Zwi, D. Gillies, S. Rosendal, C. Groth, K.B. Rasmussen, D. Gauci, R. Kirubakaran, B. Forsbøl, E. Simonsen, and C. Gluud. 2015. Methylphenidate for attention-deficit/ hyperactivity disorder in children and adolescents: Cochrane systematic review with meta-analyses and trial sequential analyses of randomised clinical trials. BMJ 351: h5203.

21. Young, S., and J. Thome. 2011. ADHD and offenders. The World Journal of Biological Psychiatry 12 (S1): 126-130.

22. Koi, P., S. Uusitalo, and J. Tuominen. 2018. Self-control in responsibility enhancement and criminal rehabilitation. Criminal Law and Philosophy 12 (2): 227-244.

23. Farahany, N. 2012. Law and behavioral morality. In Evolution and morality: Nomos LII, ed. J.E. Fleming and S. Levinson. New York: NYU Press.

24. Cheung, B.Y., and S.J. Heine. 2015. The double-edged sword of genetic accounts of criminality: Causal attributions from genetic ascriptions affect legal decision making. Personality and Social Psychology Bulletin 41 (12): 17231738. 
25. Appelbaum, P.S. 2014. The double helix takes the witness stand: Behavioral and neuropsychiatric genetics in court. Neuron 82: 946-949.

26. Tabb, K., M.S. Lebowitz, and P.S. Appelbaum. 2019. Behavioral genetics and attributions of moral responsibility. Behavior Genetics 49: 128-135.

27. Dar-Nimrod, I., and S.J. Heine. 2011. Genetic essentialism: On the deceptive determinism of DNA. Psychological Bulletin 137 (5): 800-818.

28. Schaffner, K. 2016. Behaving: What's genetic, What's not, and why should we care? Oxford: Oxford University Press.

29. Duckworth, A., and M.L. Kern. 2011. A meta-analysis of the convergent validity of self-control measures. Journal of Research in Personality 45 (3): 259-268.

30. Kotabe, H., and W. Hofmann. 2015. On integrating the components of self-control. Perspectives on Psychological Science 10 (5): 618-638.

31. Herdova, M. 2017. Self-control and mechanisms of behavior: Why self-control is not a natural mental kind. Philosophical Psychology 30 (6): 731-762.

32. Levy, N. 2011. Resisting weakness of will. Philosophy and Phenomenological Research 82 (1): 134-155.

33. Levy, N. 2017. Of marshmallows and moderation. In Moral psychology volume 5: Virtue and character, ed. W. SinnottArmstrong and C.B. Miller. Cambridge, MA: MIT Press.
34. Mischel, W., and E.B. Ebbesen. 1970. Attention in delay of gratification. Journal of Personality and Social Psychology 16 (2): 329-337.

35. Mischel, W., O. Ayduk, M.G. Berman, B.J. Casey, I.H. Gotlib, J. Jonides, E. Kross, T. Teslovich, N.L. Wilson, V. Zayas, and Y. Shoda. 2011. 'Willpower' over the life span: Decomposing self-regulation. Social Cognitive and Affective Neuroscience 6 (2): 252-256.

36. Duckworth, A., T.S. Gendler, and J.J. Gross. 2016. Situational strategies for self-control. Perspectives on Psychological Science 11 (1): 35-55.

37. Kendler, K.S., and J.H. Baker. 2007. Genetic influences on measures of the environment: A systematic review. Psychological Medicine 37 (5): 615-626.

38. Jaffee, S.R., and T.S. Price. 2008. Genotype-environment correlations: Implications for determining the relationship between environmental exposures and psychiatric illness. Psychiatry 7 (12): 496-499.

39. Hoerr, T.R. 2017. The formative five: Fostering grit, empathy, and other success skills every student needs. Alexandria, VA: ASCD.

Publisher's Note Springer Nature remains neutral with regard to jurisdictional claims in published maps and institutional affiliations. 